\title{
Role of Brain Science in the Evolution of Epilepsy Surgery
}

\author{
William Feindel*, M.D., cM., F.R.C.S.(C), D.Phil.
}

* To whom correspondence should be addressed: Montreal Neurological Institute and Hospital and the Department of Neurology and Neurosurgery, McGill University, 3801 University Street, Montreal, QC, Canada H3A 2B4

\section{INTRODUCTION}

A seizure is to the brain as a cough is to the lung - the outward sign of an internal tissue irritation. An epileptic attack thus presents as a symptom that can be expressed by many different brain disorders. The most frequent of these include trauma or infection leading to scar formation in the brain, tumors, blood vessel abnormalities, developmental anomalies, metabolic errors, and genetic defects. The pattern of a seizure may range from a generalized convulsion without warning, to focal attacks with auras or initial features of onset that reflect the part of the brain where the seizure begins, such as sensory, motor, auditory, olfactory, visual, or memory systems.

Surgical attempts to treat epilepsy can be traced back to antiquity, as documented in the scholarly account by Temkin (1). In the early-19th century, surgical approaches, most commonly related to head injuries, were based on the forthright notion that a cure came simply from removing the offending lesion - usually a brain scar from a depressed skull fracture, a dural laceration, or a cerebral contusion. It is not surprising that in the era before antisepsis, transfusion, anesthesia, or hemostasis, the results in most cases became a litany of failures, as summarized by Starr in 1893 (2). The ignorance and confusion regarding the localization of cerebral function also served as a major surgical handicap.

\section{CEREBRAL LOCALIZATION AIDING SURGERY}

Over 100 years ago, Victor Horsley (1857-1916), a neurosurgeon who performed brain stimulation experiments in primates, and Hughlings Jackson (1835-1911), a neurologist keenly aware of the emerging experimental work on cortical localization, combined intellectual forces in an operation to treat focal epilepsy (3). Their patient had suffered a head injury 15 years earlier, followed by the onset of hemiplegia and seizures. The patient had exhibited seizures that began in the leg and spread to involve the arm, wrist, fingers, and face - the characteristic "march" of attacks which are still known today as Jacksonian seizures. Jackson surmised that the irritating focus was located in the motor cortex; he urged its removal to stop the attacks. Using chloroform anesthesia, Horsley enlarged the traumatic skull defect and excised the vascular brain scar along with adjacent cortex. Two further operative cases by Horsley, with initially favorable results, stirred up considerable interest in this radical surgical approach.

Sir William Osler, the year before, had advocated the removal of brain tumors that were heralded by focal 
epilepsy (4), commenting that he "would prefer to see neurology a special department so that there would not be neurological physicians and surgeons, but medical chirurgical neurologists properly trained in the anatomical, physiological, clinical and surgical aspects of the subject" (5).

This collaboration between surgeon and neurologist, both aware of the scientific work on brain localization, established a paradigm for subsequent developments in the surgical treatment of epilepsy. Among those who made major contributions to this field were Fedor Krause (1857-1937) and Otfrid Foerster (1878-1941) in Germany (6). Krause introduced faradic stimulation, which until then had been used in animal studies to map the human motor cortex during surgery. However, he was cautious in promising improvements by surgery.

Foerster continued the detailed mapping of the human cortex, using local anesthesia so that the patient could report sensory responses during the operation (7). This made possible the maximal excision of scar tissue without damage to vital areas, as depicted in one of his operative sketches (Fig. 1). In 1928, Wilder Penfield studied for six months with Foerster;. He applied staining methods for glia, which he had learned in Del RíoHortega's laboratory in Madrid, to the microscopic examination of the vascular-glial cicatrix. He showed the cicatrix to be a common feature in the 12 surgical cases they reported (8). Their papers marked an important stage in the application of scientific techniques - cortical stimulation, sub-pial excision (to preserve circulation and minimize new scar formation), and microscopic study of the vascular-glial scar - all of which advanced the understanding of epilepsy.

\section{SCIENCE AND SURGERY: PENFIELD'S WORK}

Appointed in 1928 to head the neurosurgical service at Montreal's Royal Victoria Hospital and McGill University, Penfield assiduously exploited these techniques, bringing physiology into the operating room. He greatly extended the work of Foerster through a more detailed mapping of cortical areas subserving speech, hearing, vision, and eventually, memory function. During these early years, Penfield also edited an authoritative compendium by international experts entitled The Cytology and Cellular Pathology of the Nervous System, a three-volume work effectively summarizing what was known at that time about the basic structural changes associated with brain disorders (9).

When the Montreal Neurological Institute opened in 1934, it fulfilled Penfield's idea of a fertile setting for the interaction between scientists, surgeons, and neurologists, all addressing the problems of the nervous system and, particularly, epilepsy (10). Cellular pathology, neurophysiology, neuropsychology, and neurochemistry were all applied toward an understanding of the pathophysiological processes underlying seizures. In a long series of publications, Penfield and his associates recorded many unique observations on the functional anatomy of the human brain (11-14).

Penfield did not initially adopt Foerster and Altenburger's method of directly recording the electrical activity of the brain during operations (15). A chance encounter in 1937 led him to bring Herbert Jasper to the Institute to use the new techniques of electroencephalography (EEG) and electrocorticography (ECG). EEG refined the task of localizing the site of origin of seizure discharge by recording spikes and sharp waves that were pathognomonic for epilepsy. This greatly improved the selection of patients for surgical treatment. EEG mapped the localization of seizure activity during surgery by recording directly from the cortex and by monitoring stimulation responses $(16,17)$. The development of EEG at the Neurological Institute generated an expansion in neurophysiological research which, over the years, elucidated the complex mechanisms of epilepsy and sharpened the criteria for surgical treatment. The problem of epilepsy also stimulated research on brain tumors, the cerebral circulation, and the chemistry of the epileptogenic cortex; this led to the introduction of corticosteroid therapy for cerebral edema and the discovery of the inhibitory neurotransmitter gamma-amino butyric acid (GABA) (18). 
Stimulation and identification of the motor and sensory cortices contributed critically to the success of precisely removing lesions in those areas without subsequent neurological deficits. The following case from 1953 , with a successful outcome monitored over the past 40 years, demonstrates the practical application of this method.

\section{Case Report}

\section{M.G., age 24}

At the age of 16, M.G. temporarily lost consciousness when he fell against a wall. He subsequently experienced several "fainting" spells each year. Six months prior to admission, he developed epileptic attacks that began with plantar flexion of the toes and right foot, a painful cramp in the right calf, then muscle jerking which travelled up his right leg, culminating with a generalized convulsion. Angiogram and pneumogram showed no evidence of a lesion. However, EEG recorded epileptic spikes in the parietal region. Surgery was elected due to the focal onset of his seizure. At craniotomy, under local anesthesia, a small rounded mass was visible in the central fissure (Figs. 2A, 2B). However, the identification of the displaced motor and sensory convolutions was not possible. Stimulation points just behind the tumor at numbers $4,5,7$, and 10 gave responses of "pins and needles" in sequence from the hip down to the sole of the foot (Fig. 2C). At point 8, the patient noted contraction in the calf of his right leg, likened to the onset of his habitual seizure. The other points produced tingling in the fingers or face, which were not features of his attacks. The tumor, along with a small border of the sensory cortex, was removed by micro-suction. After excision, stimulation of the posterior bank of the motor cortex at areas 20 and 18 produced movements of the right leg, foot, and toes. However, at that time, the patient was not able to move his toes voluntarily (Fig. 2D). Post-operatively, he had mild weakness of the right foot and toes which gradually improved. The microscopic diagnosis was grade I astrocytoma. However, because of some cellular variation and the critical location of the tumor, he underwent a course of radiation therapy. Except for a single attack on the second post-operative day, M.G. has remained seizure-free for 42 years, without anti-convulsant medication for the past 30 years and with no recurrence of the tumor.

\section{SURGERY FOR TEMPORAL LOBE SEIZURES}

\section{The Anterior and Lateral Temporal Cortex}

The emergence in the late 1940's of surgery for seizures associated with the temporal lobe marked the beginning of a new era for what is now the most frequent approach for the surgical treatment of epilepsy. There were several phases in the development of such surgery, each distinguished by a substantial increase in knowledge regarding the pathophysiology of the seizures arising from the temporal lobe. Penfield and Flanigin (19) reviewed 68 temporal lobe resections carried out over the previous decade (1939 to 1949) that had arrested or controlled seizures in over one-half of the patients. The resections in this series were limited mainly to the anterolateral temporal cortex; in only 10 cases was the uncus resected, and in only 2 was a part of the hippocampus also removed. As reviewed below, Bailey and Gibbs (20) used an even more limited removal in their early series of patients, with no encroachment on mesial temporal structures. This limited anterolateral approach was influenced by the pre-operative EEG localization of the lesion as either anterolateral temporal, anterior Sylvian, or fronto-temporal (21-25). Related experimental studies were thus conducted to clarify the connections of the temporal pole $(26,27)$. This is also well illustrated by anterolateral temporal localization of EEG abnormalities registered by Jasper and two young neurosurgeons in the same series of patients studied by Penfield and Flanigin (28). In only a small number of patients was the abnormality detected in the inferior and mesial part of the lobe. 
A second phase in the surgical approach to temporal lobe seizures unfolded rapidly in the early 1950 's. Clues from experimental animal studies $(29,30)$ and stimulation responses during surgery began to point to the mesial and inferior parts of the temporal lobe as the origin of the epileptic attack $(31,32)$. For example, Penfield (33) noted several instances where stimulation in the uncinate region produced auras of the patient's attack. In one such instance a seizure with automatism was recorded by Jasper (28). It spread from the stimulation point on the inferior temporal cortex near the uncus to involve the entire temporal lobe.

The success rate of just over 50\% in the two major surgical series reported by Bailey and Gibbs (20) and Penfield and Flanigin (19) indicated that resection limited mainly to the temporal cortex did not eliminate all of the epileptogenic tissue in many patients. Indeed, in some cases these failures led Penfield to perform a second operation. Consequently, under electrocorticographic guidance, he extended the resection to include more of the uncus and hippocampus, and sometimes along the lateral temporal cortex (if performed on the non-dominant side for speech) (13,34-36).

\section{The Amygdalohippocampal Complex}

The most convincing evidence that the mesial temporal region was a crucial zone for the generation of temporal lobe seizures came in a third phase of surgical studies. This evidence was the reproduction of the patient's habitual auras by anatomically planned depth stimulation within and around the amygdala at the time of the operation (37). The resulting seizure discharge on corticography was seen to spread rapidly to encompass not only the temporal cortex but also the exposed frontal and parietal corteces (38). The surgical findings in the first patient in this series, in 1951, initiated the now convincing evidence for the role of the amygdala in temporal lobe seizures.

\section{Case Report}

P.S., age 26

P.S. had experienced a prolonged childbirth. From the age of 12, he began to suffer attacks that started with a visual aura of colored lights, and a "shock in the head." He subsequently became unresponsive, and fumbled with his clothes. Following his attack, he would have no memory of his actions. Pre-operative EEG studies showed abnormal spike activity over the lateral and inferior temporal regions on the right side. At the time of surgery, a depth electrode was directed through the second temporal convolution toward the region of the amygdala, 3.5 centimeters from the tip of the temporal lobe. One of the patient's typical small attacks was reproduced with the stimulation of the electrode tip deep in the temporal-insular sulcus, while electrodes were recording from the lateral and inferior surfaces of the temporal lobe (Fig. 3). During this period, epileptic spikes were suddenly replaced with low voltage rapid activity. Furthermore, the patient was seen to stare became unresponsive to questioning, and began plucking at the anesthetist's coat and making chewing movements, an appearance similar to that seen during his habitual attacks. The electrographic changes lasted a minute and a half, after which time the patient appeared to have recovered, but seemed unaware of the attack. There was diminution and toughening of the first temporal convolution and mesial temporal region, as well as a zone of gelatinoid tissue about the size of a small walnut deep in the temporal lobe, lateral and inferior to the ventricle, and encroaching on the amygdala. Microscopically, the lesion showed dense astrocytic gliosis and was interpreted as a grade I astrocytoma. Resection included $6 \mathrm{~cm}$ of the anterolateral cortex, as well as the mesial temporal region (amygdala and hippocampus) harboring the lesion. The patient has remained free of attacks for 37 years with no reappearance of the tumor.

\section{The Role of the Amygdala}

In 15 other patients from the aforementioned study, similar features of automatism and amnesia were reproduced through stimulation of the periamygdaloid region (Fig. 4). It was noted (38) that these findings 
corresponded to the proposed localization of "a particular variety of epilepsy" by Hughlings Jackson and others (39), just before the turn of the century. Jackson writes: "the discharge-lesions in these cases are made up of some cells, not of the uncinate gyrus alone, but of some cells of different parts of a region of which this gyrus is part - a very vague circumscription, I admit - the uncinate region" (40). The rich network of connectivity linked with the amygdala offered a valid explanation for many of the characteristic clinical features of "uncinate" attacks described by Jackson $(41,42)$. Thus, a patient's epigastric aura, at times associated with a sense of fear, was reproduced by stimulation either of the amygdala itself or of the adjacent anterior insular cortex; this area was later shown to be physiologically associated with gastric movement (43). The various emotional, autonomic, and visceral responses likewise seemed explicable in terms of the robust anatomical pathways then known to travel from the amygdala to the septal and hypothalamic regions. The initial feature of brief tonic movement associated with some temporal lobe attacks could be effected by the amygdaline efferent pathways to the striatum; chewing and swallowing movements could be explained by connections with the brainstem. The interference of the epileptic discharge with memory recordings, characterized by the profound postictal amnesia, could reasonably be related to the amygdala-hippocampal connection as well as to the projections of the amygdala to the reticular system of the brain stem (44). Curiously, direct stimulation of the hippocampus at the time of the operation rarely produced such responses, even though an epileptic abnormality is sometimes recorded from the anterior part of that structure (45).

Thus, this evidence for the amygdala and juxtaposed gray matter, including the anterior insular cortex, as a generator of temporal lobe seizures, provided a pathophysiological hypothesis that explained for the first time many of the clinical aspects of these attacks. It also indicated that the periamygdaloid zone should be included in surgical resections in order to produce the most beneficial outcome.

\section{Incisural Sclerosis}

The pathological counterpart of this physiological hypothesis was offered in a concurrent study by Earle, Baldwin, and Penfield (46). They introduced the concept of incisural sclerosis, which they postulated was due to herniation of the mesial part of the temporal lobe over the tentorial edge associated with increased intracranial pressure during a difficult birth (Fig. 5). They considered this phenomenon to cause injury to the hippocampal region, both by direct compression of the tissue and by vascular occlusion with resulting ischemia. The uncus and contiguous amygdala are even more likely to herniate into the prepeduncular space to be subject to compressive damage, although this was not emphasized by the investigators.

Based on these new assumptions, a radically different surgical approach was developed, with not only the excision of the anterolateral cortex, but also the removal of the amygdala and hippocampus, under direct vision of the mesial part of the temporal lobe. Details of this operative technique were described by Penfield and Baldwin in 1952 (47) and revised in 1961 by Penfield, Lende, and Rasmussen (48). With the application of this approach, successful surgical outcome improved from $50 \%$ to $65 \%$ (49-53).

\section{The Chicago Experience: Gibbs and Bailey}

In the meantime, Frederick and Erna Gibbs with William Lennox and others had demonstrated the EEG characteristics of the type of epilepsy that they and Foerster (54) called psychomotor seizures (21-23). Initially, their interpretations of the EEG abnormalities pointed to the frontal lobes as being the origin of the ectopic discharge. They later demonstrated that the EEG changes in this type of attack more likely involved the anterior part of the temporal lobe. Understandably, neurosurgeons were not anxious to operate solely on the basis of an electrographic focus in the absence of demonstrable pathology. With some reluctance, however, Percival Bailey proceeded cautiously in selected patients. In 1947, his technical procedure evolved from linear incisions anterior and posterior to the EEG focus on the lateral aspect of the temporal lobe, to his more common operation, in which he excised the tip of the temporal lobe and the lateral temporal gyri back to the occipitotemporal sulcus or to the level of the foot of the central sulcus (20). 
Although surgical removal of the anterior and lateral cortex was suggested by EEG findings, Bailey refrained from any attempt to resect the inferior and mesial structures of the temporal lobe. The dementia-like syndrome produced in monkeys by removal of the temporal lobes by Heinrich Klüver and Paul Bucy (55), naturally made Bailey wary of mesial temporal ablation in his patients $(20,56,57)$.

Bailey operated on 70 patients (57), 60 of whom he was able to follow for five years. Forty-seven of these patients had the "standard extirpation," or temporal corticectomy. Psychomotor attacks were suppressed in one-third of the cases and were considerably improved in another third. Overall, generalized convulsions were abolished or greatly reduced in $50 \%$ of the cases. Bailey's students, particularly John Green $(58,59)$ and Paul Crandall $(60,61)$, continued his operative procedure, but eventually extended the excision into mesial temporal structures, focusing especially on the hippocampus.

\section{The Work of Falconer and Associates}

Murray Falconer, a New Zealander who studied with Hugh Cairns at Oxford University, visited Penfield and his group in 1950 at the Montreal Neurological Institute, on his way to establishing a neurosurgical unit in London. Adopting EEG as a preoperative guide to the localization of seizure discharge, Falconer et al reported in 1953 the successful control of seizures in two children after temporal lobectomy for focal calcified lesions (62), an experience similar to that described in 1948 in four cases by Penfield and Ward (63). As he became aware of the previous Montreal results implicating the mesial temporal lobe as the origin of temporal lobe seizures, Falconer enthusiastically took up this surgical approach.

Falconer (64) and his colleagues reported 14 patients treated surgically for temporal lobe seizures. As noted in the Montreal series, $78 \%$ exhibited automatism with their seizures. The extent of Falconer's resection included temporal corticectomy with mesial temporal removal in all but the first three patients, in whom he spared the uncus and hippocampus, not realizing that they could have been removed without danger. While one patient died after surgical complications, the 13 remaining patients were followed for periods ranging from one month to two years; 10 became seizure-free, and 3 had considerable lessening of seizures (these latter patients having bitemporal electrographic abnormalities before surgery). Falconer introduced the technique of temporal lobe resection "en bloc," which included most of the hippocampus and some of the uncus in the surgical specimen. In this tissue, Meyer and Beck (65) described sclerosis in Ammon's horn of the hippocampus and raised the question of whether this was the primary cause of the epilepsy, as suggested by the Montreal group (46) and by the scholarly analysis of Sano and Malamud (66), or secondary to the ischemic changes occurring during the cyanotic stages of major seizures. In an analysis of surgical specimens, they found Ammon's horn sclerosis in 7 of 12 cases (65). Birth injury was present in the medical history of three patients; in another three the etiology appeared to be either measles encephalitis, "teething" with status epilepticus, or chicken pox. They concluded: "incisural sclerosis resulting from birth mechanism cannot be maintained as an exclusive etiology and ... later events in infancy, childhood, and early adolescence play at least an equal part." It is of interest that they found the most severe sclerosis of the hippocampus in three cases with a history of difficult birth, thus supporting the hypothesis of Earle, Baldwin, and Penfield (46). It is of significance that in both the Montreal and the London groups, small focal benign structural lesions (hamartomas, angiomas, low-grade gliomas, and cysts) encroaching on the amygdalohippocampal region were identified in almost $20 \%$ of patients with temporal lobe seizures $(63,67,68)$. Surgeons consider such patients as justifiable candidates for the surgical removal of these lesions in order to cure their seizures, (many of thses lesions can now be clearly detected and diagnosed before surgery by MRI).

\section{Application of the Montreal Procedure}

From 1953 onward, many neurosurgical centers, often involving surgeons or scientists who had studied at the Montreal Neurological Institute, took up the procedure of temporal lobe resection for the treatment of seizures. A colloquium on advances in the surgical treatment of temporal lobe epilepsy, organized by Gastaut 
and his associates in Marseilles in 1954 (69), provided an opportunity for Penfield to give an overview of the early experimental and surgical results of his team. This firmly established the important role of the mesial temporal region in the pathogenesis and surgical treatment of epilepsy (70).

\section{Variations in Surgical Resection}

A second international colloquium, with over 50 contributors, was held in 1957 at the National Institute of Health in Bethesda, Maryland, under the leadership of Maitland Baldwin and Pierce Bailey (71). An extensive review was made of the scientific and clinical aspects of temporal lobe seizures that, had become more widely adopted due to the successful surgical results following the resections that included the mesial temporal region. At this colloquium, Paulo Niemeyer (72), made aware of the role of mesial temporal structures in psychomotor epilepsy in Marseilles, described an ingenious technique to resect the amygdala and hippocampus by a transventricular approach, without removal of the overlying cortex. His surgical outcome produced cessation of seizures in $50 \%$ of a small series of patients who were followed for over one year. However, other efforts at amygdalectomy were largely unsuccessful, mainly because of difficulty in selecting patients and the formidable technical problem of adequately ablating the amygdala (73).

The successful re-introduction of resection limited to the mesial temporal region (i.e., amygdalohippocampectomy) by Wieser and Yasargil $(74,75)$ and by Oliver $(76,77)$, using advanced microsurgical techniques produced excellent control of seizures (over $80 \%$ in selected cases). Their results again supported the earlier evidence for the mesial temporal region as a critical area for the genesis of temporal lobe attacks $(13,37,38,44,78)$. However, controversy remains even today concerning major aspects of the pathogenesis of temporal lobe seizures, particularly with regard to their etiology and the relative significance of pathology involving the amygdala compared with the hippocampus (79-83). Meanwhile, Talairach, Bancaud, and their group $(84,85)$ in Paris had developed a precise anatomical approach to the surgical management of temporal lobe epilepsy by applying stereotactic techniques. This important advance was adapted by surgical centers for the accurate anatomical placement of depth electrodes in sustained electrographic investigations $(60,61,86-88)$.

\section{Memory Deficit with Bilateral Temporal Lesions}

Scoville and his group in Hartford had also produced stimulation responses from the uncus which resembled some features of temporal lobe seizures (32). This motivated him to perform bilateral resections of the mesial temporal region by a subfrontal approach in patients with schizophrenia and in a few patients with epilepsy. One of these patients, H.M., who has since become noteworthy in the annals of neuropsychology, developed a severe deficit in recent memory (89). This outcome was similar to what had been reported earlier by Milner and Penfield (90) in three patients from the Montreal series, following unilateral temporal excision in the presence of what later became recognized as bitemporal mesial temporal pathology, especially involving the hippocampus $(91,92)$. These findings, together with the observations that stimulation of the amygdala evoked ictal amnesia, directed attention to the important role of the mesial temporal structures in memory mechanisms (38).

\section{Toward a Surgical Cure}

Surgery for focal temporal seizures has become one of the most successful therapeutic measures in modern neurosurgery $(83,93,94)$. An estimated 10,000 patients have had the benefit of such surgery. The patterning of the surgical resection in order to obtain the most satisfactory surgical outcome, while at the same time minimizing neurological deficits, continues to be examined in some 100 neurosurgical centers $(94,95)$. A vast literature is now available on the anatomy, physiology, pathology, and cognitive aspects of the temporal lobe $(73,81,82,96)$. Gloor has contributed an outstanding monograph on the temporal lobe and the limbic system that summarizes this field (97). Surgical techniques have become refined and the selection of patients for the 
surgical procedure has grown far more enlightened $(78,95,98)$.

Recent surgical evidence indicates that temporal corticectomy with radical resection of the amygdala and uncus, but with minimal removal of the hippocampus, can achieve an excellent surgical outcome for many patients (Fig. 6) (80). At the same time, this reduces the possibility of memory deficits that has been attributed by Milner (99) and others to varying degrees of hippocampal damage.

The advent of magnetic resonance imaging has given a significant new dimension to the selection of patients for surgery and to the preoperative identification not only of small structural lesions in the temporal lobe (Fig. 7), but also of the presence in a majority of patients of recognizable mesial temporal sclerosis involving the amygdala and hippocampus (Fig. 8) (100). It also provides a sine qua non for monitoring the exact anatomical extent of the surgical resection to compare with the type of surgical outcome (101) reported from different centers (Figs. 9,10).

In the span of 50 years covered by this review, the effective control of temporal lobe seizures by surgical treatment has improved from $50 \%$ to almost $90 \%$, with minimal morbidity and mortality $(74,75,77,80)$. The role of mesial temporal sclerosis in the pathogenesis of temporal lobe seizures is now widely recognized (81). The significance of the amygdalohippocampal region in the pathophysiology has been well-substantiated by many stimulation studies $(60,61,82,84-87)$, by greater detail available on the anatomy and pathology of these structures $(73,83,96,97,99)$, and by the marked improvement, based on limited but radical resection of the amygdala, that has been achieved in the surgical control of temporal lobe seizures $(74-76,80)$.

\section{SURGERY SEEKS SCIENTIFIC ANSWERS}

Advances in many surgical fields have depended upon the advent of new scientific findings that enlighten the basic understanding of the anatomy and pathophysiology toward which the surgeon's attention is directed. Perhaps nowhere in the domain of surgery has the interplay of scientific and technical development been more significant than in neurosurgery. Lesions of the brain and spinal cord that were viewed 50 years ago as inoperable by the great figures in brain surgery are today dealt with successfully. Conversely, a strong influence on neuroscientific research has been effected by clinical and surgical observations. The neurosurgeon today competently deals with the surgery of aneurysms, arterial venous malformations, deepseated tumors, tumors of the skull base, and lesions of the spinal cord which have become remediable by means of technical innovations in both the diagnostic and therapeutic approaches. The use of the operating microscope and microscopic instruments, and the revolutionary computerized scanning techniques by CT, PET, and MRI, with three-dimensional anatomical depiction of the lesions have greatly refined many neurosurgical procedures. The important interaction between science and surgery is ideally illustrated by the development of the surgical treatment of epilepsy over the past five decades. Yet many questions remain to be answered. What starts a seizure? What stops it? Why do some seizures start locally and then spread to engage the entire brain, while others, less commonly, recur only as persistent focal attacks? Why is initial brain damage in early life followed, only after many years, by seizures? What is the role of the cerebral circulation in epilepsy? How are the chemical messengers in the brain involved in the cause and expression of epilepsy?

Recent findings by proton magnetic resonance spectroscopic imaging demonstrated reduced Nacetylaspartate (reflecting nerve cell loss or damage) in an epileptogenic temporal lobe, which also showed atrophy of the amygdala and hippocampus on MRI and maximal epileptic EEG abnormality (102). The results point to the correct localization of the side of the seizure focus in $80 \%$ of patients. Studies by positron emission tomography (PET) showed reduced glucose activity in the epileptic temporal lobe (Fig. 11), increased uptake of opioids and dopamine in the mesial temporal region, but decreased benzodiazepine. Meyer, Reutens, et al. (103) have found enhanced uptake of $\left\{{ }^{11} \mathrm{C}\right\}$-L-Deprenyl consistent with a denser population of astrocytes in the cerebral scar or sclerosis (Fig. 11). This finding is reminiscent of the pioneering microscopic observations of Del Río-Hortega and Penfield in 1927 on the high density of reactive 
astrocytes and microglia in a cerebral wound (104), and the description by Foerster and Penfield in 1928 of the vasoglial cicatrix in surgical specimens (8).

\section{CONCLUSION}

This historical outline highlights how neuroscience has aided the evolution of a selective surgical cure for seizures and how, in return, clinical findings often pointed the way to new avenues of scientific inquiry that enhanced our basic understanding of epilepsy. Since the early 1970's, the revolutionary advances in brain imaging have elucidated the pathological and neurochemical changes in epilepsy and also provided elegant three-dimensional visualization to the surgeon for pre-operative diagnosis, precise anatomical navigation during the operation, and exact monitoring of the surgical resection to correlate with clinical outcome. This syzygy between science and surgery offers the most effective means for extending the successful surgical treatment of many patients with epilepsy.

\section{ACKNOWLEDGEMENTS}

The author thanks Drs. Ernst Meyer, David Reutens, Fred Andermann, and François Dubeau for kindly providing the PET studies for Figure 11. The figures from the papers of Wilder Penfield are reproduced with permission of the literary executors of the estate of Wilder Penfield. This review is part of a project on the history of the Montreal Neurological Institute, Brain Science and Surgery, supported by the Hannah Institute for the History of Medicine, Donner Canadian Foundation, and the Thomas Willis Fund (Montreal Neurological Institute).

\section{REFERENCES}

1. Temkin O. The Falling Sickness: A History of Epilepsy from the Greeks to the Beginning of Modern Neurology. Baltimore, MD: Johns Hopkins University Press; 1945.

2. Starr MA. Brain Surgery. New York, NY: William Wood; 1893.

3. Horsley V. Brain-Surgery. British Medical Journal 2: 670-675; 1886.

4. Osler W. A contribution to Jacksonian epilepsy and the situation of the leg centre. American Journal of Medical Science 89: 31-37; 1885.

5. Osler W. Discussion, British Medical Association meeting. Lancet 2: 334; 1907.

6. Feindel W, Leblanc R, Villemure J-G. History of the surgical treatment of epilepsy. In: Greenblatt SH, Dagi TF, Epstein MH, eds. A History of Neurosurgery. Park Ridge, IL: American Association of Neurological Surgeons, chapter 23; 1995.

7. Foerster O. The motor cortex in man in the light of Hughlings Jackson's doctrines. Brain 59: 135-159; 1936.

8. Foerster O, Penfield, W. Der Narbenzug am und im Gehirn bei traumatischer Epilepsie in seiner Bedeutung für das Zustandekommen der Anfälle und für die therapeutische Bekämpfung derselben. Zeitschrift fur Neurologie und Psychiatrie 125: 475-572; 1930.

9. Penfield, W, ed. Cytology and Cellular Pathology of the Nervous System. 3 Vols. New York, NY: Paul B. Hoeber; 1932.

10. Penfield W. The significance of the Montreal Neurological Institute. In: Neurological Biographies and 
Addresses; Foundation Volume Published for the Staff, to Commemorate the Opening of the Montreal Neurological Institute of McGill University (on 27th September, 1934). London: Oxford University Press, $37-54 ; 1936$.

11. Penfield W, Erickson, TC. Epilepsy and Cerebral Localization; A Study of the Mechanism, Treatment and Prevention of Epileptic Seizures. Springfield, IL: Charles C Thomas, 623; 1941.

12. Penfield, W, Rasmussen, T. The Cerebral Cortex of Man. A Clinical Study of Localization of Function. New York, NY: Macmillan, 248; 1950.

13. Penfield W, Jasper H. Epilepsy and the Functional Anatomy of the Human Brain. Boston, MA: Little, Brown \& Co., 896; 1954.

14. Penfield W, Robert L. Speech and Brain-Mechanisms. Princeton, NJ: Princeton University Press, 286; 1959.

15. Foerster O, Altenburger H. Elektrobiologische Vorgänge an der menschlichen Hirnrinde. Dtsch A Nervenheilk 135: 277-288; 1935.

16. Jasper HH. Electroencephalography. In: Penfield W, Erickson TC, eds. Epilepsy and Cerebral Localization. Springfield, IL: Charles C Thomas, 380-454; 1941.

17. Jasper HH. Electrical activity of the brain. A study of the mechanism, treatment and prevention of epileptic seizures. Annual Review of Physiology 3: 337-398; 1941.

18. Feindel W. Brain physiology at the Montreal Neurological Institute: some historical highlights. Journal of Clinical Neurophysiology 9: 176-194; 1992.

19. Penfield W, Flanigin H. Surgical therapy of temporal lobe seizures. Archives of Neurology and Psychiatry 64: 491-500; 1950.

20. Bailey P, Gibbs FA. The surgical treatment of psychomotor epilepy. JAMA 145: 365-370; 1951.

21. Gibbs EL, Gibbs FA, Fuster B. Psychomotor epilepsy. Archives of Neurology and Psychiatry 60: 331$339 ; 1948$.

22. Gibbs FA, Davis H, Lennox WG. The electro-encephalogram in epilepsy and in conditions of impaired consciousness. Archives of Neurology and Psychiatry 34: 1133-1148; 1935.

23. Gibbs FA, Lennox WG, Gibbs EL. The electro-encephalogram in diagnosis and in localization of epileptic seizures. Archives of Neurology and Psychiatry 36: 1225-1235; 1936.

24. Jasper HH. Electroencephalography. In: Penfield W, Erickson TC, eds. Epilepsy and Cerebral Localization. Springfield, IL: Charles C Thomas, 380-454; 1941.

25. Jasper HH, Kershman J. Electroencephalographic classification of the epilepsies. Archives of Neurology and Psychiatry 45: 903-943; 1941.

26. Marsan CA, Stoll J Jr. Subcortical connections of the temporal pole in relation to temporal lobe seizures. Archives of Neurology and Psychiatry 66: 669-686; 1951.

27. Stoll J, Ajmone-Marsan C, Jasper HH. Electrophysio-logical studies of subcortical connections of the 
anterior temporal region in cat. Journal of Neurophysiology 14: 305-316; 1951.

28. Jasper HH, Pertuisset B, Flanigin H. EEG and cortical electrograms in patients with temporal lobe seizures. Archives of Neurology and Psychiatry 65: 272-290; 1951.

29. Gastaut H, Vigouroux R, Corriol J, et al. Effets de la stimulation électrique (pars électrodes à demeure) du complexe amygdalienne chez le chat non narcosé. Journal de Physiologie (Paris) 43: 740-756; 1951.

30. Kaada BR. Somato-motor, automatic and electrocorticographic responses to electrical stimulation of "rhinencephalic" and other structures in primates, cat and dog. A study of responses from the limbic subcallosal, orbito-insular piriform and temporal cortex, hippocampus-fornix and amygdala. Acta Physiologica Scandinavica 24 (Suppl 83): 1-285; 1951.

31. Feindel W. Temporal lobe seizures. In: Vinken PJ, Bruyn GW, eds. Handbook of Clinical Neurology. Vol. 15: The Epilepsies. Amsterdam: North-Holland, 87-106; 1974.

32. Liberson WT, Scoville WB, Dunsmore RH. Stimulation studies of the prefrontal lobe and uncus in man. Electroencephalography and Clinical Neurophysiology 3: 1-8; 1951.

33. Penfield W. The cerebral cortex in man. I. The cerebral cortex and consciousness. Archives of Neurology and Psychiatry 40: 417-442; 1938.

34. Feindel W. Recall, amnesia and experiential responses from stimulation of the human amygdala. In: Squire LR, Mishkin M, Shimamura A, eds. Learning and Memory: Discussions in Neuroscience. Geneva: Elsevier, 72-80; 1990.

35. Feindel W. Development of surgical therapy of epilepsy at the Montreal Neurological Institute. Canadian Journal of Neurological Sciences 18: 549-553; 1991.

36. Penfield W. Epileptic automatism and the centrencephalic integrating system. Research Publications Association for Research in Nervous and Mental Disease 30: 513-528; 1952.

37. Feindel W, Penfield W, Jasper H. Localization of epileptic discharge in temporal lobe automatism. Transactions of the American Neurological Association 77: 14-17; 1952.

38. Feindel W, Penfield W. Localization of discharge in temporal lobe automatism. Archives of Neurology and Psychiatry 72: 605-630; 1954.

39. Jackson $\mathrm{JH}$, Beevor CE. Case of tumour of the right temporosphenoidal lobe, bearing on the localisation of the sense of smell and on the interpretation of a particular variety of epilepsy. Brain 12: 346-357; 1889.

40. Jackson JH, Stewart P. Epileptic attacks with a warning of a crude sensation of smell and with the intellectual aura (dreamy state) in a patient who had symptoms pointing to gross organic disease of the right temporo-sphenoidal lobe. Brain 22: 534-549; 1899.

41. Jackson JH. On a particular variety of epilepsy ("intellectual aura"), one case with symptoms of organic brain disease. Brain II: 179-207; 1888.

42. Jackson H, Colman WS. Case of epilepsy with tasting movements and "dreamy state" - very small patch of softening in the left uncinate gyrus. Brain 21: 580-590; 1898.

43. Penfield W, Faulk ME. The insula: further observations on its function. Brain 78: 445-470; 1955. 
44. Feindel W. Response patterns elicited from the amygdala and deep temporoinsular cortex, In: Sheer DE, ed. Electrical Stimulation of the Brain. Austin, TX: University of Texas Press, 519-531; 1961.

45. Gloor P, Feindel W. Affective behaviour and temporal lobe. In: Monnier M, ed. Physiologie und Pathophysiologie des Vegetativen Nervensystems. II: Pathophysiologie. Stuttgart: Hippokrates-Verlag, 685$716 ; 1963$.

46. Earle KM, Baldwin M, Penfield W. Incisural sclerosis and temporal lobe seizures produced by hippocampal herniation at birth. Archives of Neurology and Psychiatry 69: 27-42; 1953.

47. Penfield W, Baldwin M. Temporal lobe seizures and the technique of subtotal temporal lobectomy. Annals of Surgery 136: 625-634; 1952.

48. Penfield W, Lende RA, Rasmussen T. Manipulation hemiplegia. An untoward complication in the surgery of focal epilepsy. Journal of Neurosurgery 18: 760-777; 1961.

49. Falconer MA, Serafetinides EA, Corsellis JAN. Etiology and pathogenesis of temporal lobe epilepsy. Archives of Neurology 10: 233-248; 1964.

50. Rasmussen T, Feindel W. Temporal lobectomy: review of 100 cases with major hippocampectomy. Canadian Journal of Neurological Sciences 18: 601-602; 1991.

51. Rasmussen TB. Cortical resection for medically refractory focal epilepsy: results, lessons and questions. In: Rasmussen TB, Marino R, eds. Functional Neurosurgery. New York, NY: Raven Press, 253-269; 1979.

52. Rasmussen, T. Cortical resection in the treatment of focal epilepsy. Advances in Neurology 8: 139-154; 1974.

53. Rasmussen, T, Jasper H. Temporal lobe epilepsy: indication for operation and surgical technique. In: Baldwin M, Bailey P, eds. Temporal Lobe Epilepsy. Springfied, IL: Charles C Thomas, 440-460; 1958.

54. Zülch KJ. Otfrid Foerster. 1873-1941. Surgical Neurology 1: 313-316; 1973.

55. Klüver H, Bucy, PC. Preliminary analysis of functions of the temporal lobes in monkeys. Archives of Neurology and Psychiatry 42: 979-997; 1939.

56. Flanigin HF, Hermann BP, King DW, et al. The history of surgical treatment of epilepsy in North America prior to 1975. In: Lüders H, ed. Epilepsy Surgery. New York, NY: Raven Press, 19-35; 1991.

57. Herman BP, Stone JL. A historical review of the epilepsy surgery program at the University of Illinois Medical Center: the contributions of Bailey, Gibbs and collaborators to the refinement of anterior temporal lobectomy. Journal of Epilepsy 2: 155-163; 1989.

58. Green JR. Temporal lobectomy, with special reference to selection of epileptic patients. Journal of Neurosurgery 26: 584-593; 1967.

59. Green JR. Percival Bailey oration. Surgical treatment of epilepsy during childhood and adolescence. Surgical Neurology 8: 71-80; 1977.

60. Crandall PH. Historical trends: a conical spiral. In: Apuzzo MLJ, ed. Neurosurgical Aspects of Epilepsy. Park Ridge, IL: American Association of Neurological Surgeons, 3-13; 1991. 
61. Crandall PH, Walter RD, Rand RW. Clinical applications of studies on stereotactically implanted electrodes in temporal lobe epilepsy. Journal of Neurosurgery 20: 827-840; 1963.

62. Falconer MA, Pond DA, Meyer A, et al. Temporal lobe epilepsy with personality and behavior disorders caused by an unusual calcifying lesion. Report of 2 cases in children relieved by temporal lobectomy. Journal of Neurosurgery and Psychiatry 16: 234-244; 1953.

63. Penfield W, Ward A. Calcifying epileptogenic lesions. Hemangioma calificants; report of a case. Archives of Neurology and Psychiatry 60: 20-36; 1948.

64. Falconer MA. Discussion on the surgery of temporal lobe epilepsy: surgical and pathological aspects. Proceedings of the Royal Society of Medicine 46: 971-974; 1953.

65. Meyer A, Falconer MA, Beck E. Pathological findings in temporal lobe epilepsy. Journal of Neurosurgery and Psychiatry 17: 276-285; 1954.

66. Sano K, Malamud N. Clinical significance of sclerosis of the cornu ammonis. Ictal "psychic phenomena." Archives of Neurology and Psychiatry 70: 40-53; 1953.

67. Falconer MA, Hill D, Meyer A, et al. Treatment of temporal-lobe epilepsy by temporal lobectomy. A survey of findings and results. Lancet I: 827-835; 1955.

68. Mathieson G. Pathology of temporal lobe foci. Advances in Neurology II: 163-185; 1975.

69. Morin G, Gastaut H. Colloquium concerning normal and pathological anatomical problems raised by epileptic discharges. Neurobiological Laboratory, Faculty of Medicine, Marseilles. Marseille, Nov 15-18, 1954 (Reproduced also by U.S. Department of Health, Education and Welfare, Public Health Service, Washington, DC).

70. Penfield W. Epileptogenic lesions. Acta Neurologica Psychiatrica Belgica 56: 75-88; 1956.

71. Baldwin M, Bailey P, eds. Temporal Lobe Epilepsy. Springfield, IL: Charles C Thomas; 1958.

72. Niemeyer P. The transventricular amygdala-hippocampectomy in temporal lobe epilepsy. In: Baldwin M, Bailey P, eds. Temporal Lobe Epilepsy. Springfield, IL: Charles C Thomas, 461-482; 1958.

73. Aggleton JP, ed. The Amygdala. New York, NY: Wiley-Liss; 1992.

74. Wieser HG, Yasargil MG. Selective amygdalohippocampectomy as a surgical treatment of mesiobasal limbic epilepsy. Surgical Neurology 17: 445-447; 1982.

75. Yasargil MG, Teddy PJ, Roth R. Selective amygdalo-hippocampectomy. Operative anatomy and surgical technique. Advances and Technical Standards in Neurosurgery 12: 93-123; 1985.

76. Olivier A. Surgical management of complex partial seizures. In: Nistico G, Di Perri R, Meinardi H, eds. Epilepsy: An Update on Research and Therapy. New York, NY: Alan R Liss, 309-324; 1983.

77. Olivier A. Surgery of epilepsy: overall procedure. In: Apuzzo MLJ, ed. Neurosurgical Aspects of Epilepsy. Park Ridge, IL: American Association of Neurological Surgeons, 117-148; 1991.

78. Feindel W. Toward a surgical cure for epilepsy: the work of Wilder Penfield and his school at the Montreal Neurological Institute. In: Engel J Jr, ed. Surgical Treatment of the Epilepsies, 2nd ed. New York, 
NY: Raven Press, 1-9; 1993.

79. Feindel W, Rasmussen T. Temporal lobectomy with amygdalectomy and minimal hippocampal resection: review of 100 cases. Canadian Journal of the Neurological Sciences 18: 603-605; 1991.

80. Gloor P. Mesial temporal sclerosis: historical background and an overview from a modern perspective. In: Lüders H, ed. Epilepsy Surgery. New York, NY: Raven Press, 689-703; 1991.

81. Gloor P. The role of the amygdala in temporal lobe seizures. In: Aggleton JP, ed. The Amygdala. New York, NY: Wiley-Liss, 505-538; 1992.

82. Pringle CE, Blume WT, Munoz DG, et al. Pathogenesis of mesial temporal sclerosis. Canadian Journal of the Neurological Sciences 20: 184-193; 1993.

83. Olivier A. Temporal resections in the surgical treatment of epilepsy. Epilepsy Research - Supplement 5: $175-188 ; 1992$

84. Bancaud J, Talairach J, Bonis A, et al. La Stéréo-Électroencéphalographie dans l'Épilepsie. Informations Apportées par l'Investigation Fonctionnelle Stéréotaxique. Paris: Masson et Cie; 1965.

85. Talairach, J, David M, Tournoux P. L'Exploration Chirurgicale Stéréotaxique du Lobe Temporale dans l'Épilepsie Temporale. Repérage Anatomique Stéréotaxique et Technique Chirurgicale. Paris: Masson; 1958.

86. Ojemann GA, Ward AA Jr. Stereotactic and other procedures for epilepsy. Advances in Neurology 8: 241$263 ; 1975$.

87. Gloor P, Olivier A, Quesney LF, et al. The role of the limbic system in experimental phenomena of temporal lobe epilepsy. Annals of Neurology 12: 129-144; 1982.

88. Halgren E, Walter RD, Cherlow, DG, et al. Mental phenomena evoked by electrical stimulation of the human hippocampal formation and amygdala. Brain 101: 83-117; 1978.

89. Scoville WB, Milner B. Loss of recent memory after bilateral hippocampal lesions. Journal of Neurology Neurosurgery and Psychiatry 20: 11-21; 1957.

90. Milner B, Penfield W. The effect of hippocampal lesions on recent memory. Transactions of the American Neurological Association 80: 42-48; 1955.

91. Penfield, W, Mathieson G. Memory. Autopsy findings and comments on the role of hippocampus in experiential recall. Archives of Neurology 31: 145-154; 1974.

92. Penfield W, Milner B. Memory deficit produced by bilateral lesions in the hippocampal zone. Archives of Neurology and Psychiatry 79: 475-497; 1958.

93. Feindel W. Temporal lobe seizures. In: Vinken PJ, Bruyn GW, eds. Handbook of Clinical Neurology. Vol 15: The Epilepsies. Amsterdam: North-Holland, 87-106; 1974.

94. Lüders H, ed. Epilepsy Surgery. New York, NY: Raven Press; 1991.

95. Engel J Jr, ed. Surgical Treatment of the Epilepsies, 2nd ed. New York, NY: Raven Press; 1993.

96. Bruton CJ. The Neuropathology of Temporal Lobe Epilepsy. New York, NY: Oxford University Press; 
1988.

97. Gloor P. The Temporal Lobe and Limbic System. New York, NY: Oxford University Press; 1996.

98. Wyllie E, ed. The Treatment of Epilepsy: Principles and Practice. Philadelphia, PA: Lea \& Febiger; 1993.

99. Milner B. Psychological defects poduced by temporal lobe excisions. Research Publications - Association for Research in Nervous and Mental Disease 36: 244-257; 1958.

100. Kuzniecky R, de la Sayette V, Ethier R, et al. Magnetic resonance imaging in temporal lobe epilepsy: pathological correlations. Annals of Neurology 22: 341-347; 1987 .

101. Feindel W, Robitaille Y, Tampieri D, et al. Electroencephalography, magnetic resonance imaging and pathology in patients treated surgically for temporal lobe epilepsy. Canadian Journal of Neurological Sciences 18: 577-579; 1991.

102. Cendes F, Andermann F, Dubeau F, Arnold, DL. Proton magnetic resonance spectroscopic images and MRI volumetric studies for lateralization of temporal lobe epilepsy. Magnetic Resonance Imaging. 13(8) (in press); 1995.

103. Meyer E, Reutens D, Andermann F, Dubeau, F. $\left\{{ }^{11} \mathrm{C}\right\}$-L-Deprenyl uptake in temporal lobe epilepsy. American Academy of Neurology (Abstract); 1996.

104. Del Río-Hortega P, Penfield W. Cerebral cicatrix: The reaction of neuroglia and microglia to brain wounds. Bulletin of Johns Hopkins Hospital 41: 278-303; 1927

\section{BIOGRAPHY}

Dr. William Feindel, M.D., cM. (McGill, 1945), is Professor of Neurosurgery and Director Emeritus of the Montreal Neurological Institute and Hospital, where he studied with Drs. Wilder Penfield, William Cone and Herbert Jasper. His student article in the McGill Medical Journal, "Notes on the development of hemostasis in Neurosurgery," appeared in the issue of December 1944. He is also Chancellor of Acadia University, Nova Scotia.

Copyright (C) 1995 by MJM 